\title{
Industrial Cooperation in Mechanical Engineering as a Tool of Innovative Orientation of Economic Development
}

\author{
Kodolova T.A. \\ Economics Department \\ Vyatka State University \\ Kirov, Russia \\ toropova-1992@mail.ru
}

\author{
Suvorova L.A. \\ Economics Department \\ Vyatka State University \\ Kirov, Russia \\ larsuvorova@mail.ru
}

\begin{abstract}
The article considers industrial cooperation as a tool for fast implementation of innovative developments in the engineering industry. Industrial cooperation has a significant impact on the formation of sustainable innovative development of the economy and contributes to expansion of science-intensive export-oriented engineering production with high added value. The aim of the study is to determine the importance of expanding and intensifying the industrial, organizational and technological interactions of participants in cooperative collaboration in mechanical engineering for enhancing the transition to the production of innovative products. The subject of the study is economic and innovation-oriented relations of participants of industrial cooperation in mechanical engineering that arise in the process of their cooperation. The study substantiated the hypothesis about the effect of interest in the multifaceted interaction of participants of cooperative activities on the innovative development of the mechanical engineering industry. The novelty of the paper is provided by the justification of the need to build a mechanism for initiating and activating of innovation driven relations between participants in cooperative interactions in mechanical engineering to strengthen the innovative development of the economy. The article analyzes the efficiency of the implementation of the Programs for the development of regional cooperation of industrial enterprises in the Volga Federal District (VFD), gives a comparative review of the economic indicators of VFD constituent entities. The methods of institutional theory, analysis and synthesis, logical, statistical and comparative methods are used in the study. In conclusion, the article presents recommendations on increasing the efficiency of initiating and activating of innovatively directed relations between engineering enterprises and related industries, education institutions and authorities.
\end{abstract}

Keywords: economic development, innovative interests, industrial cooperation, mechanical engineering, import substitution

\section{INTRODUCTION}

Mechanical engineering is one of the drivers of the Russian economy, characterized by huge export and innovation potential. One of the possible ways to increase the competitiveness of domestic engineering enterprises is to create powerful production cooperation. Production cooperation represents long and stable relations between participants for the joint production of one product suitable for independent implementation. Cooperative relations in mechanical engineering are distinguished by a targeted focus, variety of implementation methods; they contribute to expand the share of export-oriented products and increase their science intensity.

In modern conditions, production cooperation is turning to become the reproductive base of the scientific, technical and socio-economic progress of any state; it represents the basis for world economic processes, international industrial cooperation, regional economic integration, and globalization of the world economy.

The strategic goal of developing industrial cooperation in mechanical engineering is to ensure the formation of a competitive engineering complex. One of the target tools to support this strategy is to strengthen the innovative activity of participants in the operation of cooperative chains.

Currently, engineering enterprises are in great need of innovation. Their production capacities are loaded not optimally; they face difficulties with distribution of products due to their narrow specialization. At the same time, intraregional consumer demand for engineering products is not fully satisfied, so its import prevails. These circumstances indicate the need to find efficient mechanisms for mobilizing joint innovative resources for the creation of importsubstituting equipment in cooperative collaboration between 
the engineering enterprises themselves and other interested parties.

\section{LITERATURE REVIEW AND RESEARCH METHODS}

In 1937 Ronald Harris Coase in his fundamental article "The Nature of the Company" stated that if transactions are accompanied by expenses (that is, the functioning of the market is costly); the "institutions" become crucial in the economy [1]. In 1960, in his work "Problems of Social Costs" $\mathrm{R}$. Coase stated that the main function of institutions is to create coordination and cooperation between people [2]. Competition, considered in classical and neoclassical economic theories as the main driving force of economic development, was not such according to R. Coase's works. He believed that cooperation, collaboration, and other forms of collective action between people and enterprises can play an equally important role [3]. The evolution of approaches to cooperation is considered in the works of D. Como, where cooperation is interpreted as an agreement of economically independent, competitive units, united by a common goal, objectives and achievement of a common result, each of which has its own structure for management functions [4]. J. Streichi emphasized that cooperation is a long-term agreement between several enterprises, based on the division of social labor, providing for coordination of functional powers, united by a common goal of increasing production and making profit [4].

Scientists define the modern economy as the economy of knowledge and innovation [5-12]. The transition to development strategies based on knowledge and innovations has brought to life new partnership relations, which include industrial cooperation. Existing theoretical knowledge and practical experience contribute to the consideration of cooperation as a scientific field, revealing the multidimensional nature of economic and innovation-oriented relations between cooperation participants.

The authors of this article propose to consider industrial cooperation taking into account an identification of such activity focus of cooperation participants as innovative activity. The industrial cooperation in mechanical engineering is defined by the authors as innovative economic activity of enterprises together with scientific and educational institutions and authorities, which contributes to strengthen traditional market positions and conquer new markets through the production of knowledge-based export-oriented products.

The program-targeted approach when using cooperative interaction in industry is implemented in the formation of regional Programs for industrial cooperation development (hereinafter referred to as Programs). The practical significance of these Programs is characterized by the degree of conformity of the formed integrated measures with regional specifics and unique competitive advantages.

Programs for the development of industrial cooperation of several entities of the Volga Federal District in the framework of this article were studied. They are focused on ensuring the innovative development of regional mechanical engineering industries. They propose the transformation of the main approaches to cooperation deals and regulate the transition to partnership relations in deals on intellectual property exchanging and innovative developments. The priority of these deals over deals for raw materials supply, semi-finished products and finished products is aimed at stimulating innovation activity within the participants in the cooperation themselves. This makes it possible to intensify their joint activities, contributes to the logical transition of partnerships to more complex forms of cooperation, such as formation of integrated and cluster associations.

The problem regarding the choice of mechanisms for the development of innovative processes remains one of the key problems for engineering enterprises. The authors propose a mechanism for initiating and activating of innovatively directed relations as a systemic process of building up production and technological ties between cooperative interaction participants in mechanical engineering to strengthen the innovative development of the economy (Figure 1).

In the context of the post-industrial economy formation, modern industrial cooperation is focused on the innovative development of the engineering industry. It realizes the innovative potential of mechanical engineering, promotes coordinated quality interactions of all production components - science, finance, industry, and entrepreneurship. Innovatively directed development of industrial cooperation involves building rational proportions in the development of high-tech industries, expanding vertical and horizontal ties between enterprises, scientific and educational organizations, and authorities. The priority criteria for industrial cooperation in mechanical engineering at the present stage of development are based on unique competitive advantages of industry enterprises, such as high scientific potential, unique products and technologies, and highly qualified human resources.

\section{RESULTS AND DISCUSSION}

The development and implementation of territorial sectoral Programs for regional cooperation development of industrial organizations in the Volga Federal District have been carried out in the Udmurt Republic and Ulyanovsk Region. The purpose of the Programs for the development of industrial cooperation is defined as creation of organizational, economic and social conditions for the development of industrial cooperation. Created in Perm Region, the Center for Industrial Cooperation provides support to small and medium businesses in Perm Region: the promotion of small and medium enterprises to large companies and holdings; the search and placement of production orders, the search for potential contractors for business tasks fulfillment.

After analyzing the existing mechanisms for the development of cooperation in the regions [13-16], it should be noted that while making decisions on industrial cooperation development it is crucial for the enterprises to strive to achieve competitive advantages that can increase their competitiveness accordingly. The success of enterprises in both domestic and foreign markets is determined by the impact of innovative and foreign economic effects.

The innovative effect reflects an increase in innovative potential as well as an increasing of new product output, and 


\section{The instrument for initiating and enhancing the innovation focus of relations} between participants in industrial cooperation

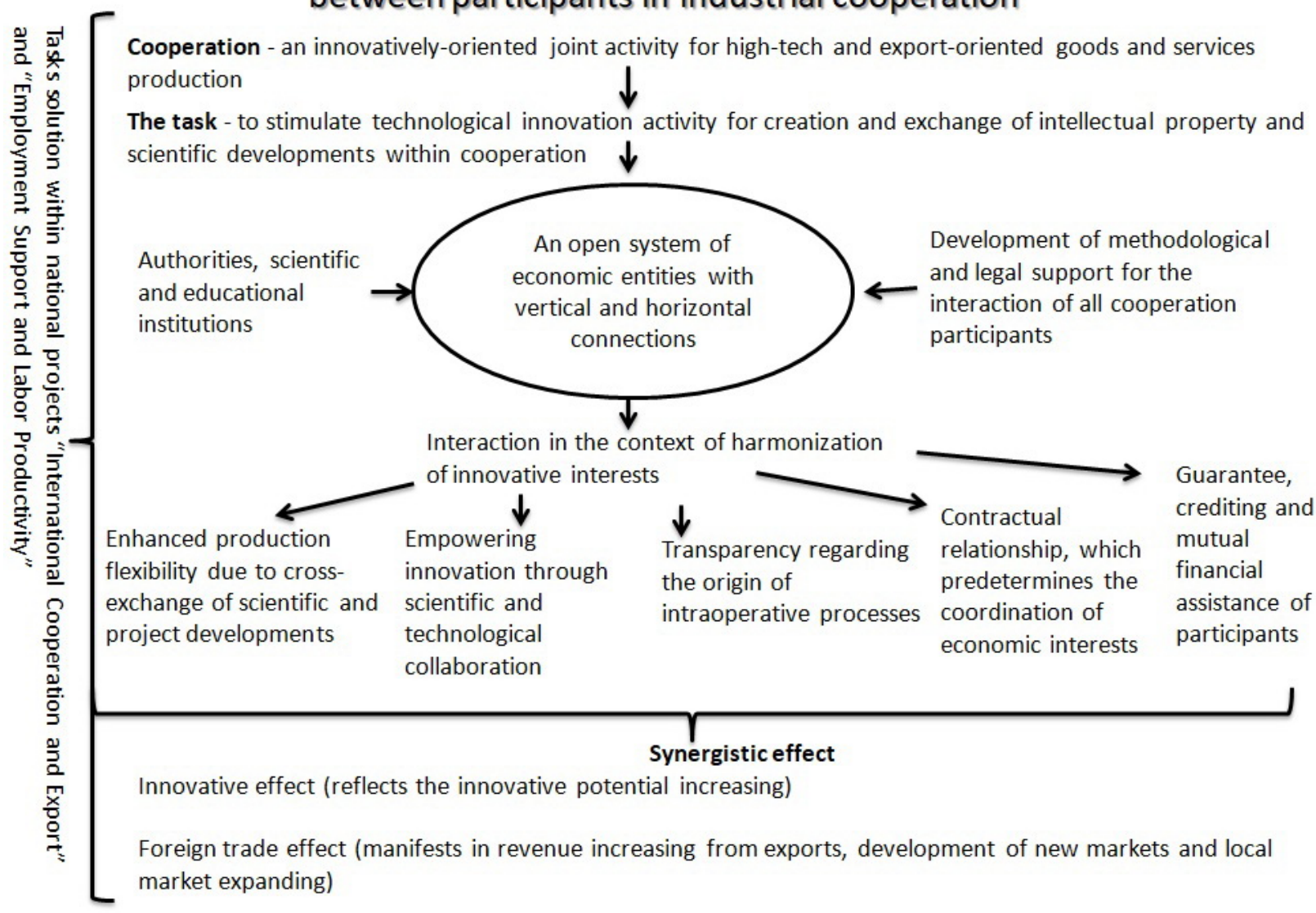

Fig. 1. Mechanism for initiating and enhancing the innovative focus of industrial cooperation relations

new technologies usage. The most important indicators used for assessing the innovative developments intensity in production include the proportion of innovative goods, works, services, in the total volume of goods shipped, work and services performed, and the costs for research of the regions (Figure 2).

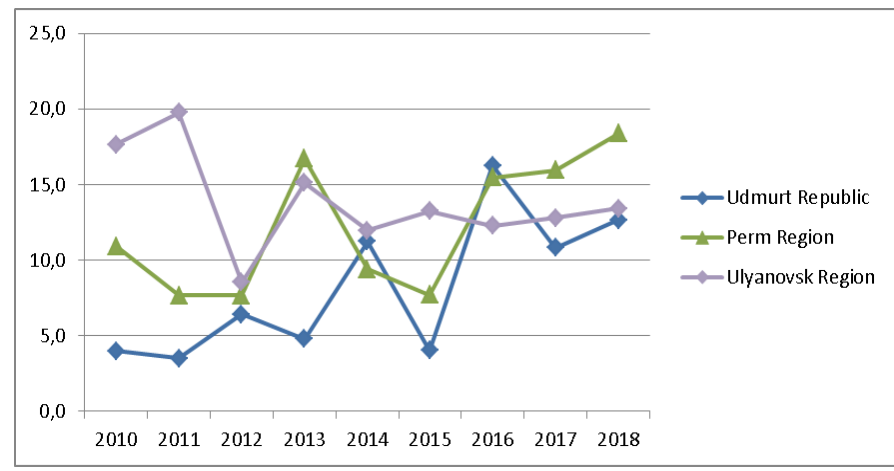

Fig, 2. Share of innovative goods, works, services in the total volume of goods shipped, works and services performed, \% (Source: calculated by the authors based on data [17])
The largest share of innovative goods and services in 2011 was observed in Ulyanovsk Region. First of all, this may be explained by the completion of the program "Concept of development of regional production cooperation system in Ulyanovsk Region". The dynamics of indicators in Perm Region also confirms the effectiveness of Industrial cooperation center. In 2016, the share of innovative products of enterprises increased by $7.8 \%$. During the reviewed period the Udmurt Republic demonstrated a dynamic growth in the share of innovative products, which raised the Republic's place in the regions' top for innovative development.

Thus, the creation of industrial cooperation contributes to the growth of innovation activity, which is a prerequisite for the region to transform it into a sustainable innovative development trajectory (Figure 3).

The analysis of internal regional costs for research and development reveals a positive trend of expenditures for research and development. The largest expenses are borne by Perm Region and Ulyanovsk Region (by absolute value).

The need for a qualitative change in the commodity structure of Russian exports was put forward as a main strategic goal "International cooperation and export" [18]. 
Production of high-tech products with high added value has a significant impact on the formation of sustainable innovative development; first of all, this is the production of a mechanical engineering complex.

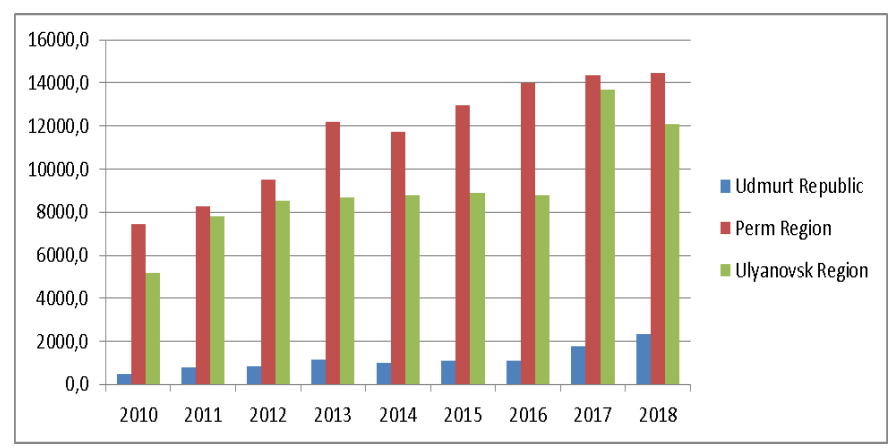

Fig, 3. Dynamics of internal costs for research and development by regions (Source: calculated by the authors based on data [16])

In accordance with the Decree of the President of the Russian Federation "On national goals and strategic objectives for the development of the Russian Federation for the period up to 2024", the main goal is to achieve the volume of exports of non-primary non-energy goods in the amount of $\$ 250$

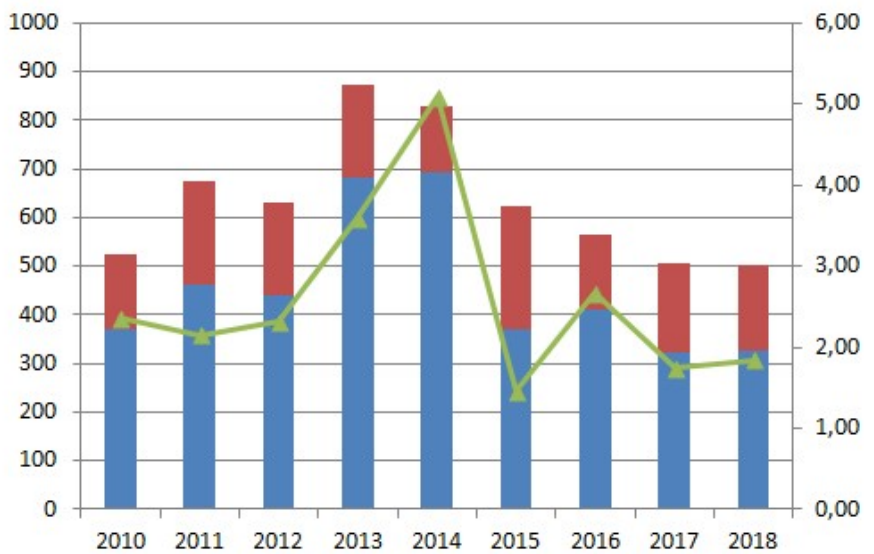

Perm Region

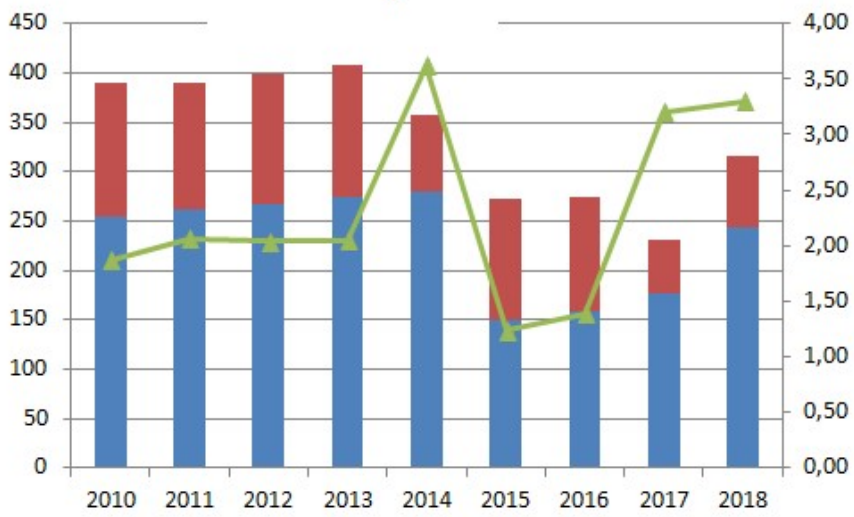

Udmurt Republic

Fig. 4. Foreign economic activity of mechanical engineering complex by regions billion, including mechanical engineering products of $\$ 50$ billion per year [19].

It is particularly important and at the same time difficult to identify the foreign trade effect. On the one hand, it is manifested in revenue increasing from exports. However, the demand of mechanical engineering enterprises is largely observed due to the import of products. Thus, only an increase in the share of exports of Russian mechanical engineering products and a reduction in the share of imports can demonstrate positive dynamics, and, consequently, the identification of foreign trade effect (Figure 4).

The analysis of the data shows that the degree of dependence of the regions on imports of high-tech products is quite heavy. At the same time, positive trends can be noted. Thus, imports of mechanical engineering products of Perm Region have decreased significantly, and on the contrary exports have increased by 1.3 from 2014. In Ulyanovsk Region the ratio of imports and exports of mechanical engineering products for the studied period has decreased, which also confirms the positive dynamics.

Based on the study, there is an increase in efficiency of the implementation of Programs for the development of industrial cooperation in the regions of the VFD in terms of obtaining
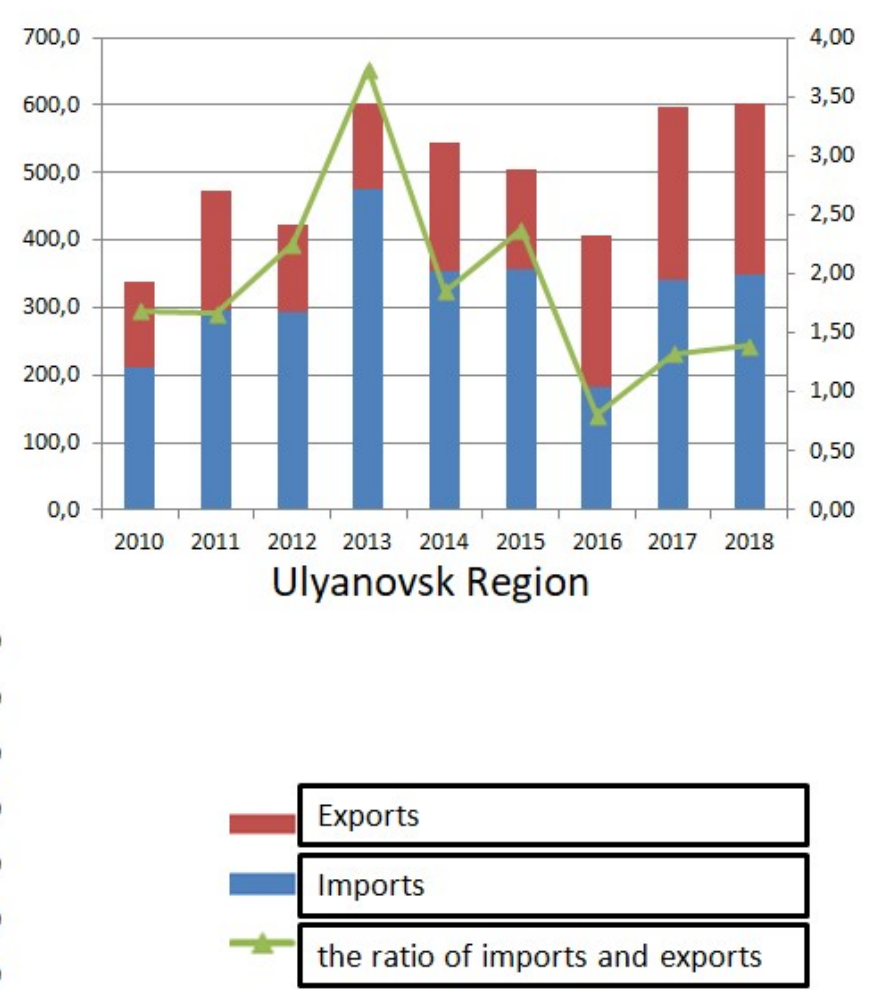
innovative and foreign trade effect. Further activities within the development of industrial cooperation will contribute to the growth of domestic production, increase exports, raise the manufacturability of mechanical engineering industries and enhance innovation.

\section{CONCLUSION}

Summarizing all above data, it is revealed that the efficiency of the innovative focus of cooperative ties contributes to giving positive dynamics to the economic development of the mechanical engineering industry. Productions, organizational and technological actions of participants in cooperative collaboration are interrelated and mutually reinforcing directions of innovative development. These close interactions create favorable conditions and opportunities for the development of various forms of cooperation and the identification of innovative competencies.

The increase in research and development expenses contributes to the creation of effective economic ties and economically viable cooperation chains. The exchange of intellectual property makes it possible to load optimally the production capacities of engineering enterprises and activate intra-regional consumer demand. The high profitability of cooperation participants provides the possibility of reproduction processes self-financing and the production base updating.

Dynamism of production cooperation diversity has a synergistic basis and is founded on the self-organization ability of its participants that leads to obtaining new features, i.e. competitive advantages. Production cooperation can be represented as a positive dynamic process of the qualitative transition of the economic system to a new updated level, where all its participants are more competitive.

As generalized recommendations on assessing the efficiency of initiation and activation of innovatively directed relations between engineering enterprises and related industries, scientific and educational organizations and authorities, the following can be noted:

- to ensure the participation of locally registered enterprises in the regional programs implementation;

- to determine the list of the most important products for assessing the local capabilities to produce similar competitive products;

- to organize the involvement of small enterprises and entrepreneurs to expand cooperative ties based on subcontracting;

- to develop possible methods for involving bank capital into financing of cooperative processes.

The proposed recommendations require both mechanical engineering enterprises and regional authorities to make significant qualitative production, organizational and technological transformations, and an objective need to find effective forms of management and regulation of the cooperation process.

\section{REFERENCES}

[1] R. H. Coase, "The Nature of Firm", M: Delo, 2001, 360 p.

[2] M. F. Sabirova, "Couse's theorem as an instrument of economic-political studies of modern Russia", in Business, Management and Law, Russia, 2014, no. 2 (30), pp. 27-31.

[3] R. H. Coase, "Firm, market and law", trans. from English, M.: New Publishing House, Russia, 2007, 224 p.

[4] D. A. Malov, "International cooperative movement: the history of formation and development prospects", International Scientific and Practical Conference "Prospects for the socio-economic development of the modern state in society": collection of materials, Russia, Cheboksary: Cheboksary Cooperative Institute, 2014, pp. 427-434.

[5] A. V. Fomina, O. N. Berduygina, and F. F. Shatsky, "Industrial cooperation and its influence on sustainable economic growth", in Entrepreneurship and Sustainability Issues, 2018, vol. 5, no. 3, pp. 467479.

[6] B. Weber and S. Heidenreich, "Improving innovation capabilities by cooperation: Examining effects of core network management functions and relational mechanisms in the industrial goods sector", in International Journal of Innovation Management, 2016, vol. 20, no. 07, pp. 1650074.

[7] K. D. Busygin, "Sustainable development of innovative industrial enterprises in the context of intercompany cooperation", Monograph., M.: AP "Science and Education", Russia, 2015, 160 p.

[8] L. Pennacchio, G. Piroli, and O. Ardovino, "THE ROLE OF R\&D COOPERATION IN FIRM INNOVATION", in International Journal of Innovation and Technology Management, 2018, vol. 15, no 1, 1850003 p.

[9] E. A. Sidorova, "Innovative development of the BRICS countries, prerequisites and prospects for cooperation", in Bulletin of International Organizations: Education, Science, New Economy, Russia, 2018, no. 1, pp. 34-50.

[10] N. V. Pakhomova and S. A. Smirnov, "Innovative Economics: Structural Priorities and Indicators", in Bulletin of St. Petersburg University, Russia, 2011, no. 4, pp. 3-21.

[11] A. A. Urasova, "Regional industrial complex in the digital age: information and communication change", in Economy of Region, Russia, 2019, no. 3, pp. 684-694.

[12] D. B. Odlis, "Innovative solutions to the problems of the development of the regional engineering complex in the conditions of market transformation", in Theory and Practice of Social Development, Russia, 2011, no. 4, pp. 284-289.

[13] G. Ya. Belyakova and D. A. Fokina, "Features of the development of industrial cooperation of machine builders within the EAEU", in Fundamental Research, Russia, 2017, no. 11-1, pp. 190-194.

[14] D. I. Akhmetzyanov, "Production cooperation in the engineering sector of the Perm Territory", in MASTER'S JOURNAL Perm National Research Polytechnic University, Russia, 2016, no. 1, pp. 419-429.

[15] V. V. Filatov, "Regional aspects of the development of the machinebuilding complex of the Russian Federation", International Scientific and Practical Conference "New information technologies in science": collection of articles, Part 1, Russia, Ufa: International Center for Innovation Research "Omega science", 2016, pp. 234-241.

[16] A. V. Makarov and V. A. Trapeznikov, "The formation of a program for the development of industrial cooperation in the region", in Economy of Region, Russia, 2011, no. 3 (27), pp. 175-183.

[17] Regions of Russia. Socio-economic indicators. 2018, Statistical Digest, Rosstat, M., Russia, 2018, 1162 p.

[18] The passport of the national project (program) "International Cooperation and Export", approved by the Presidium of the Presidential Council for Strategic Development and National Projects (protocol no. 16 dated 12.24.2018)

[19] Decree of the President of the Russian Federation of 05.07.2018 no. 204 "On national goals and strategic objectives of the development of the Russian Federation for the period until 2024" [Electronic resource]. Available at: http://publication.pravo. gov.ru/Document/View/0001201805070038. 